\title{
Lymph node involvement by enteropathy-like indolent NK-cell proliferation
}

\author{
Jean-Louis Dargent ${ }^{1} \cdot$ Nicolas Tinton ${ }^{2} \cdot$ Mounir Trimech $^{3} \cdot$ Laurence de Leval $^{3}$ (D)
}

Received: 2 June 2020 / Revised: 17 June 2020 / Accepted: 7 July 2020 / Published online: 21 July 2020

(C) The Author(s) 2020

\begin{abstract}
Natural killer (NK)-cell enteropathy (NKCE) and lymphomatoid gastropathy (LG) are closely related lymphoproliferative disorders (LPDs) composed of mature and Epstein-Barr virus (EBV)-negative NK-cells. Although these uncommon and indolent lymphoid proliferations mostly arise within the gastrointestinal (GI) tract as their designations implies, a few cases have been reported outside the GI tract. We hereby describe a unique case of lymph node infiltration by such EBV-negative NK-cell proliferation fortuitously found during routine examination of a gallbladder resected for biliary lithiasis. The histologic, phenotypic, and molecular features of this NK-cell proliferation, which were very similar if not identical to those previously reported in NKCE or LG, suggest that similar indolent EBV-negative NK-cell LPDs may also occasionally involve lymph nodes.
\end{abstract}

Keywords Indolent NK-cell lymphoproliferative disorder · NK-cell enteropathy $\cdot$ Lymphomatoid gastropathy $\cdot$ Lymph node Gallbladder · Gastrointestinal

\section{Introduction}

Several cases of a particular Epstein-Barr virus (EBV)negative natural killer (NK)-cell proliferation occurring mainly in the gastrointestinal (GI) tract and following an indolent course have been recently reported [1-16]. The clinico-pathologic spectrum of this rare lymphoproliferative disorder (LPD), initially described as lymphomatoid gastropathy and more commonly referred to as NK-cell enteropathy (NKCE) [1-16], remains not fully characterized. Herein, we describe an EBV-negative NK-cell proliferation that was fortuitously found in the cystic duct lymph node of a cholecystectomy.

Laurence de Leval

Laurence.DeLeval@chuv.ch

1 Service d'Anatomie Pathologique, Institut de Pathologie et de Génétique (IPG), Gosselies, Belgium

2 Service de Chirurgie, Grand Hôpital de Charleroi (GHDC), Charleroi, Belgium

3 Institute of Pathology, Department of Laboratory Medicine and Pathology, Lausanne University Hospital and Lausanne University, Lausanne, Switzerland

\section{Case report}

A 37-year-old Caucasian male with no previous medical history underwent laparoscopic cholecystectomy for symptomatic biliary lithiasis. The gallbladder contained gallstones, had a moderately thickened wall, and no obvious mucosal lesion. A 1.3-cm lymph node was adjacent to the cystic duct, which was free of stone. Histologically, the gallbladder showed hyperplastic and inflammatory changes consistent with xanthogranulomatous cholecystitis, and the cystic duct was normal. Beside benign reactive changes with $\mathrm{B}$ cell follicular hyperplasia, the lymph node was partially obliterated by a relatively circumscribed and vaguely nodular infiltrate of monotonous medium-sized cells with moderately abundant pale cytoplasm (Fig. 1a-b). No cytoplasmic granules were visible. Nuclei were round to oval with slightly irregular contours, somewhat open chromatin and inconspicuous nucleoli (Fig. 1c). There were rare apoptotic bodies, few mitoses, and scattered histiocytes. By immunohistochemistry, the pale cells were positive for $\mathrm{CD} 2$, cytoplasmic CD3 $( \pm)$, CD7, CD56, perforin, granzyme B $( \pm)$ and T-cell intracellular antigen (TIA)-1, and negative for T-cell receptor $\beta$ (TCR $\beta$ ), TCR $\delta, C D 1 \mathrm{a}, \mathrm{CD} 4, \mathrm{CD} 5, \mathrm{CD} 8, \mathrm{CD} 10, \mathrm{CD} 20$, CD23, CD30, CD34, CD57, CD79a, CD123, CXCL13, ICOS, PD1, S100, and myeloperoxydase (Fig. 2). The Ki67 proliferation index was approximately $10 \%$. EBV- 

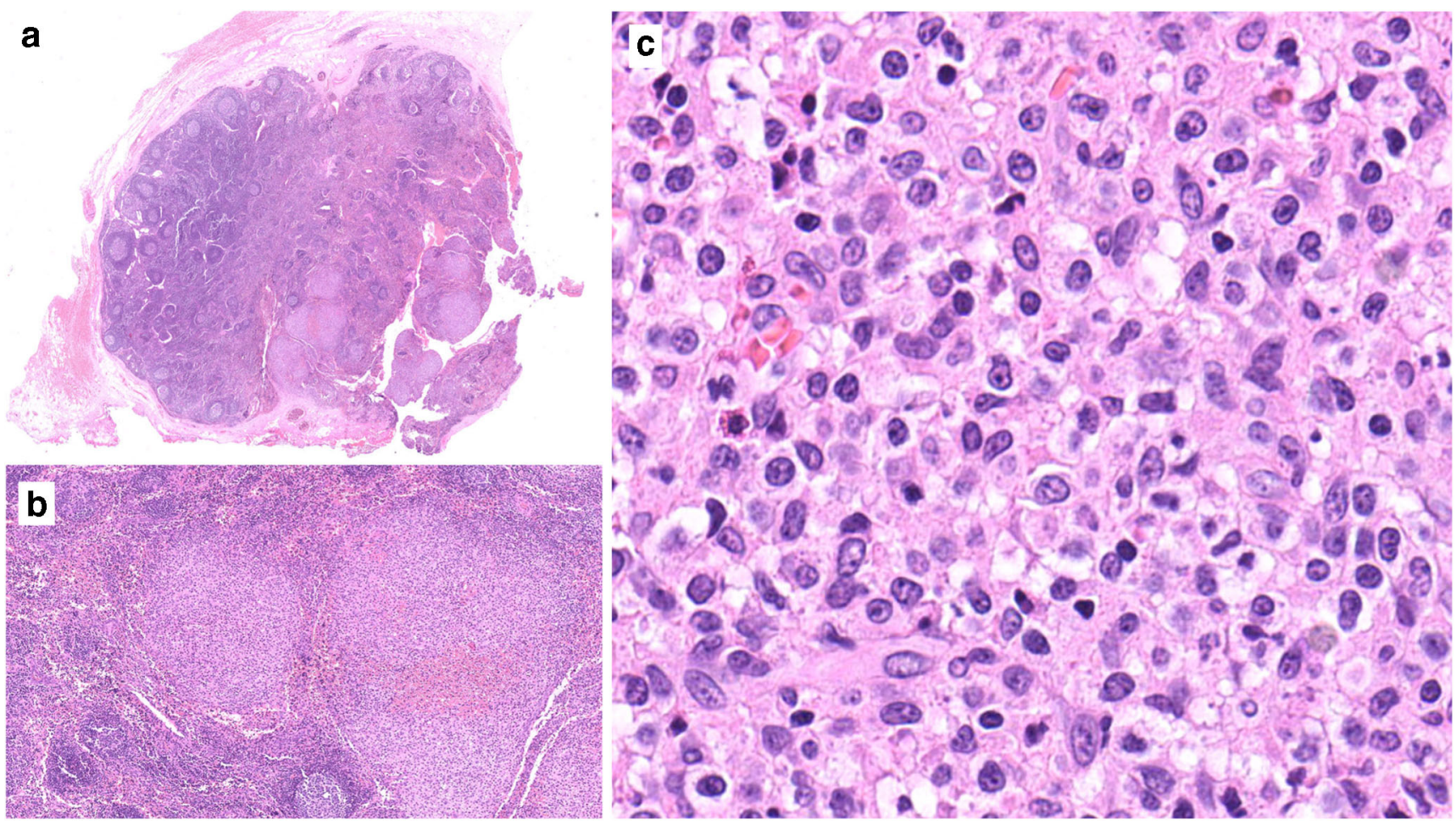

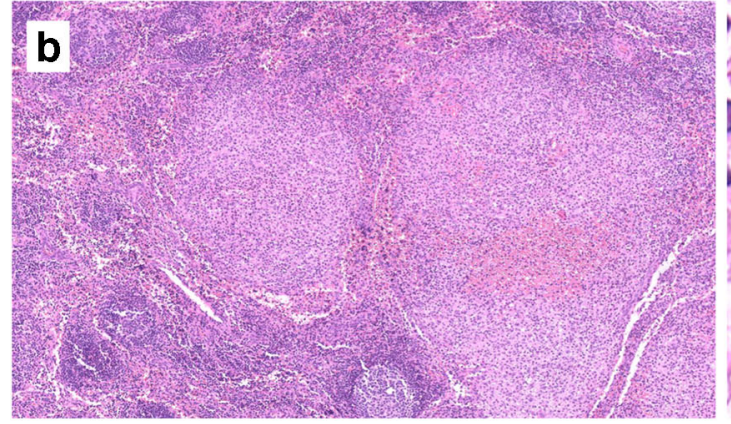

Fig. 1 Histopathology of the lymph node. a Panoramic view showing partial replacement of the lymphoid tissue by relatively circumscribed nodules (lower right). Elsewhere, the nodal architecture is preserved with follicular hyperplasia. b The nodules are composed of monotonous and medium-sized lymphoid cells. c Cytological features at high power. Hematoxylin and eosin stain; original magnifications $\times 8, \times 50$, and $\times$ 400 , respectively encoded RNA (EBER) in situ hybridization (ISH) was negative. Polymerase chain reaction-based clonality analysis did not demonstrate clonal rearrangement of the TR genes (TRB and TRG). Next-generation sequencing (NGS) analysis using a panel of 26 genes designed for peripheral T-cell lymphomas (ARID1A, ATM, BCOR, CARD11, CCR4, CD28, CTNNB1, DDX3X, DNMT3A, FYN, IDH2, IRF4, JAK1, JAK3, KMT2D, PIK3CD, PLCG1, PRKCB, RHOA, SETD2, STAT3, STAT5B, TET2, TNFRSF1B, TP53, VAV1) disclosed a mutation involving the exon 4 of the DNMT3A gene (c.178-9C $>\mathrm{T}$ ) with a variant allele fraction (VAF) of $46 \%$, also described in the general population at a very low frequency and interpreted as a constitutional variant. FISH analysis using a JAK2 break apart probe (9p24) showed a normal hybridization pattern.

Based on these findings, an "enteropathy-like" NK-cell lymphoproliferation was considered. An extensive clinical work-up, including peripheral blood analysis, computed tomography (CT) scan, positron emission tomography (PET) scan, esophagogastroduodenoscopy, and colonoscopy, did not demonstrate any abnormal finding. Multiple biopsies from the stomach, duodenum, ileum, and colon showed essentially normal histology. PET scan disclosed a small thyroid nodule, benign by fine needle aspiration cytology. No further therapy was given. The patient is still asymptomatic 18 months later.

\section{Discussion}

Except for the unusual location within a lymph node, the features of this EBV-negative NK-cell proliferation are very similar to those described in NKCE, of which forty-seven cases have been reported [1-16]. The clinical features of these uncommon lymphoid proliferations, which share some features with indolent T-cell LPDs of the GI tract $[17,18]$, are summarized in Table 1 . There were 19 men and 28 women ranging in age from 9 to 76 years, only four patients were younger than 30 years, and the median age was 57.5 years [1-16]. With the exception of three cases [11, 14, 16], all patients were diagnosed with GI involvement [1-16]. Twenty-eight cases occurred in the stomach, duodenum, or in several upper GI sites; seven cases involved the lower GI tract; and in nine cases there was concomitant involvement of the upper and lower GI mucosa [1-16]. In roughly half of the cases (21/44) the patients had no specific complaints and the lesions were fortuitously discovered by endoscopy performed for check-up or screening [1-16]. Conversely, in 23/44 cases various symptoms were recorded, mostly vague or nonspecific abdominal or epigastric pain or discomfort, sometimes diarrhea or weight loss, for which clinical workup and endoscopic investigations eventually led to the diagnosis [1-16]. At endoscopy, the altered mucosa often consists of 

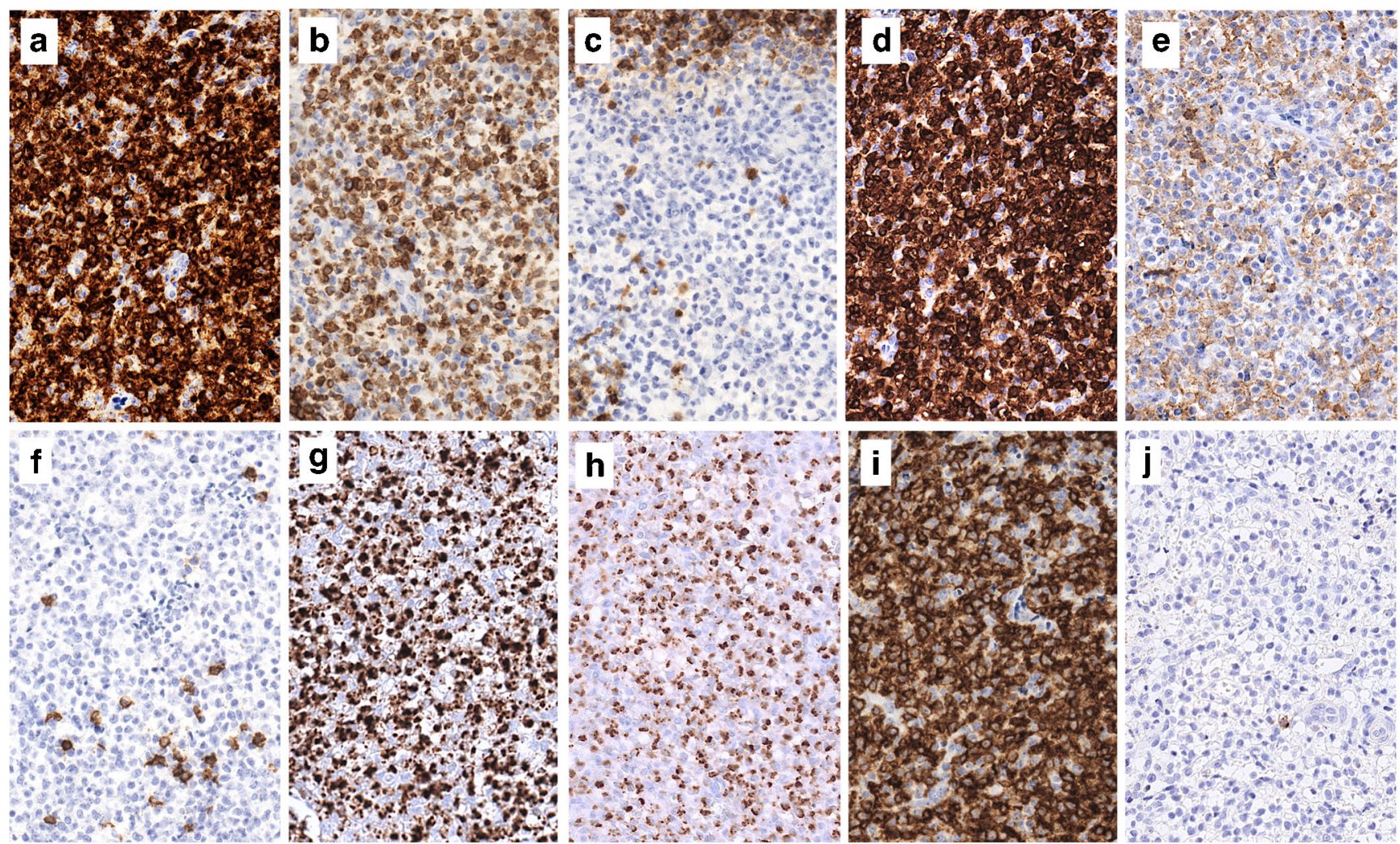

Fig. 2 Immunophenotypic characteristics of the lymphoproliferation. The cells are positive for CD2 (a), cytoplasmic CD3 (b), CD7 (d), CD56 (i), perforin (g), and TIA1 (h). They are negative for CD5 (c),

CD4 (e), CD8 (f), and CD57 (j). CD4 and CD8 stain a few reactive T cells or histiocytes. Immunoperoxidase; original magnification $\times 300$

erythematous, flat or polypoid lesions, superficial erosions, or ulcers [1-16]. The clinical course is particularly indolent, with spontaneous resolution or persistence despite various kinds of therapies, for up to several years in some patients [1-16]. Unlike indolent T-cell LPDs of the GI tract, progression to a more aggressive disease or nodal involvement has not yet been documented, although imaging studies showed enlarged regional lymph nodes in some patients $[4,9]$. The cases reported outside the GI tract were incidental microscopic discoveries during gallbladder examination in two patients (33and 65-year-old) who underwent cholecystectomy for chronic cholecystitis or biliary colic, and a symptomatic vaginal mass in a 34 -year-old woman $[11,14,16]$. The case reported here is the first example of nodal involvement by an indolent EBVnegative NK-cell LPD similar to NKCE or LG. Interestingly, the involved lymph node was adjacent to the gallbladder, suggesting that outside of the GI tract, the biliary region may be a site of predilection for this disorder, which may possibly originate from a peculiar tissue-specific NK-cell subset, as has been proposed in some studies $[3,5,9,13]$.

NKCE is usually composed of medium to large-sized lymphoid cells that contain variable amounts of pale cytoplasm, nuclei with slightly irregular contours, open chromatin, and inconspicuous nucleoli [1-16]. In most cases, atypical cells diffusely infiltrate the lamina propria of the mucosa [1-16].
Occasionally, there may be some spilling into the glandular epithelium. Extension into the submucosa was reported in some cases [1-16]. Importantly, there is no marked cellular atypia, no significant mitotic activity, and no angiocentricity, angiodestructive growth or necrosis [1-16]. Immunophenotypic features of the reported cases show a very homogeneous profile consistent with mature NK cell, including expression of cytoplasmic CD3, CD7, CD56, and cytotoxic granules-associated molecules in virtually all cases [1-16]. CD2 expression is detected in a subset of the cases $(68 \%)$, a few CD $8+$ cases have been reported $(4 / 43,9 \%)[9,10,12]$, while CD4, CD5, and TCR isoforms ( $\beta$ or $\gamma$ chains) are consistently negative. Ki-67 proliferation index is typically reported as low or quantified lower than $50 \%$, but in $5 /$ 26 cases (19\%) a higher fraction of cycling cells was reported, up to $90 \%$. EBER ISH was negative in all cases, and no clonal rearrangement of the TR genes was found in any of the cases where clonality was investigated [1-16].

Some studies have suggested that an abnormal immune response, possibly related to yet unknown antigen(s), could underline NKCE pathogenesis $[3,5,9,13,16]$. In one patient with high titers of antigliadin antibodies, the lesions regressed significantly under gluten-free and lactose-free diet [1]. Several gastric cases had concomitant Helicobacter pylori infection $[2,6-8,10,12]$. However, overall, no firm relationship with a specific factor or condition could be demonstrated 


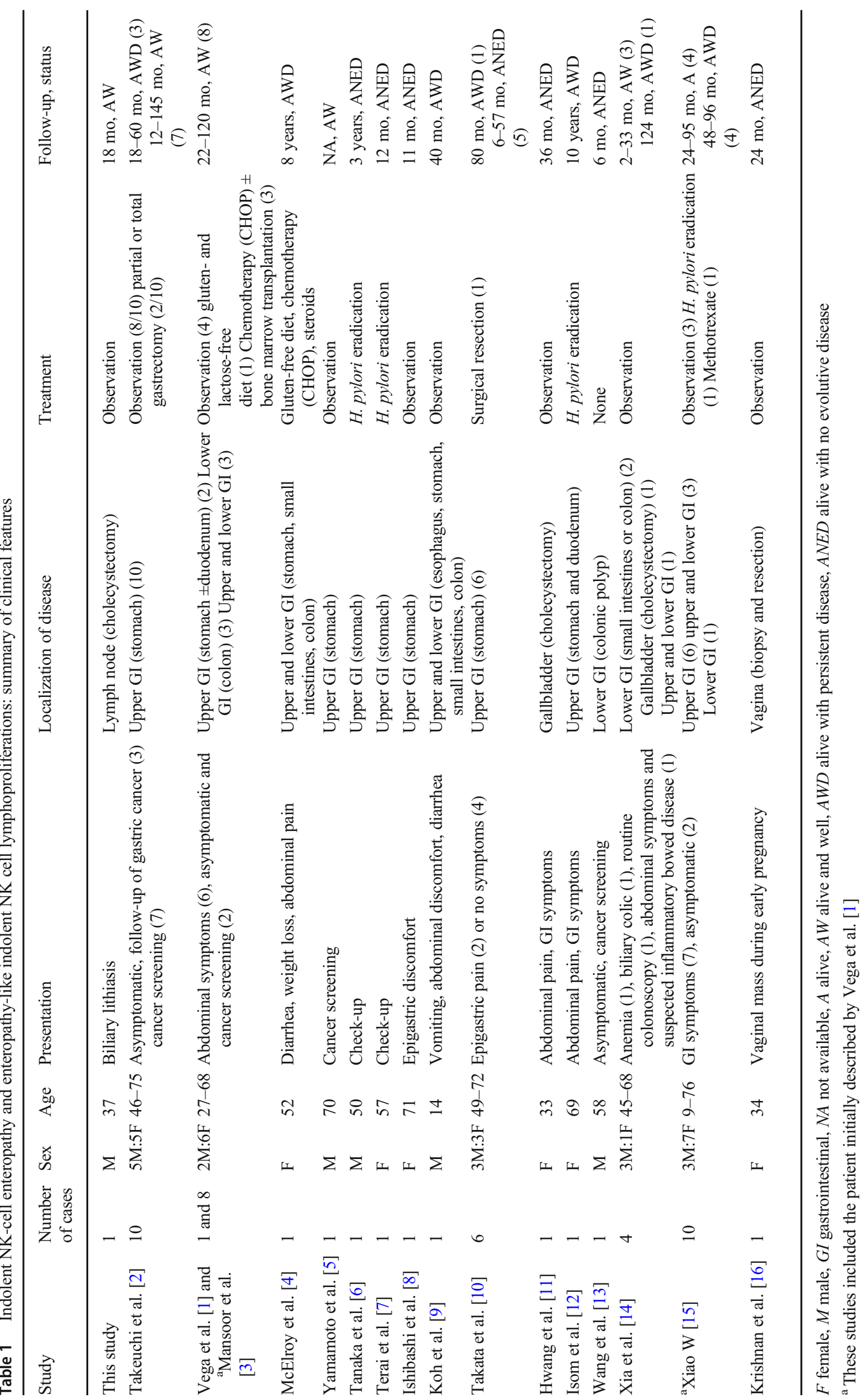


[1-16]. In a recent study using a large hematology-oriented NGS panel, a somatic JAK3 mutation consisting of a small in frame deletion in exon 12 was identified in $3 / 10$ patients with NKCE [15]. Other non-recurrent mutations involving PTPRS, AURKB, AXL, ERBB 4, IGF1R, PIK3CB, CUL3, CHEK2, $R U N X 1 T 1, C I C, S M A R C B 1$, and SETD5 were found in seven cases [15]. In a few cases subject to extensive genetic testing including 3/10 NKCE and the vaginal mass recently reported $[15,16]$, however, no mutation was identified. In our patient, NGS analysis of 26-genes T-cell lymphoma panel found no pathogenic mutation and in particular no JAK3 deletion, but one cannot exclude genetic aberration(s) in other genes not tested in this panel. Thus, indolent NK-cell LPDs may represent a spectrum ranging from polyclonal to clonal, the latter related to mutations promoting the clonal expansion of NK cells, notably those deregulating the JAK/STAT pathway which represent oncogenic drivers in a variety of other NK/T-cell neoplasms.

Due to significant prognostic differences and therapeutic implications, indolent NK-cell LPDs must be distinguished from other mature NK-cell neoplasms like aggressive NKcell leukemia and extranodal NK/T-cell lymphoma, nasaltype. Marked cellular atypia, significant mitotic activity, cellular necrosis, angiocentricity, or angiodestructive pattern of growth and positive EBER ISH are features of aggressive NKcell disorders and clues against NKCE [1-16]. Distinction from the exceptional cases of EBV-negative NK-cell lymphoma may be more challenging due to EBV-negativity, but those cases as the one reported by Koo et al. in the small bowel show clearly malignant features [17]. Because of clear cells and possible epitheliotropism, NKCE may first elicit consideration of a marginal zone B cell lymphoma or monomorphic epitheliotropic intestinal T-cell lymphoma (MEITL). Even after immunophenotyping, the distinction with MEITL may remain difficult, given expression of antigens common to $\mathrm{T}$ and NK cell lineages and strong CD56 positivity in both conditions [14]. However, MEITL typically presents as a tumor mass, harbors clonal TR gene rearrangements, and recurrent SETD2 alterations, not found in NKCE [18].

In conclusion, we describe herein a case of nodal EBVnegative NK-cell proliferation, akin to NKCE. This observation further expands the spectrum of NKCE outside the GI tract. Awareness of pathologic features of these underrecognized LPDs is advisable, in order to avoid overdiagnosis and inappropriate treatment.

Author contributions JLD and LDL performed pathologic examination and wrote the paper; NT contributed essential clinical information; MT performed molecular analysis. All authors gave final approval for publication.

Funding Open access funding provided by University of Lausanne.

\section{Compliance with ethical standards}

Conflict of interest The authors declare that they have no conflict of interest.

Open Access This article is licensed under a Creative Commons Attribution 4.0 International License, which permits use, sharing, adaptation, distribution and reproduction in any medium or format, as long as you give appropriate credit to the original author(s) and the source, provide a link to the Creative Commons licence, and indicate if changes were made. The images or other third party material in this article are included in the article's Creative Commons licence, unless indicated otherwise in a credit line to the material. If material is not included in the article's Creative Commons licence and your intended use is not permitted by statutory regulation or exceeds the permitted use, you will need to obtain permission directly from the copyright holder. To view a copy of this licence, visit http://creativecommons.org/licenses/by/4.0/.

\section{References}

1. Vega F, Chang CC, Schwartz MR, Preti HA, Younes M, Ewton A, Verm R, Jaffe ES (2006) Atypical NK-cell proliferation of the gastrointestinal tract in a patient with antigliadin antibodies but not celiac disease. Am J Surg Pathol 30:539-544. https://doi.org/ 10.1097/00000478-200604000-00017

2. Takeuchi K, Yokoyama M, Ishizawa S, Terui Y, Nomura K, Marutsuka K, Nunomura M, Fukushima N, Yagyuu T, Nakamine H, Akiyama F, Hoshi K, Matsue K, Hatake K, Oshimi K (2010) Lymphomatoid gastropathy: a distinct clinicopathologic entity of self-limited pseudomalignant NK-cell proliferation. Blood 116: 5631-5637. https://doi.org/10.1182/blood-2010-06-290650

3. Mansoor A, Pittaluga S, Beck PL, Wilson WH, Ferry JA, Jaffe ES (2011) NK-cell enteropathy: a benign NK-cell lymphoproliferative disease mimicking intestinal lymphoma: clinicopathologic features and follow-up in a unique case series. Blood 117:1447-1452. https://doi.org/10.1182/blood-2010-08-302737

4. McElroy MK, Read WL, Harmon GS, Weidner N (2011) A unique case of an indolent CD56-positive T-cell lymphoproliferative disorder of the gastrointestinal tract: a lesion potentially misdiagnosed as natural killer/T-cell lymphoma. Ann Diagn Pathol 15:370-375. https://doi.org/10.1016/j.anndiagpath.2010.05.007

5. Yamamoto J, Fujishima F, Ichinohasama R, Imatani A, Asano N, Harigae H (2011) A case of benign natural killer cell proliferative disorder of the stomach (gastric manifestation of natural killer cell lymphomatoid gastroenteropathy) mimicking extranodal natural killer/T-cell lymphoma. Leuk Lymphoma 52:1803-1805. https:// doi.org/10.3109/10428194.2011.573030

6. Tanaka T, Megahed N, Takata K, Asano N, Niwa Y, Hirooka Y, Goto H (2011) A case of lymphomatoid gastropathy: an indolent CD56-positive atypical gastric lymphoid proliferation, mimicking aggressive NK/T cell lymphomas. Pathol Res Pract 207:786-789. https://doi.org/10.1016/j.prp.2011.09.012

7. Terai T, Sugimoto M, Uozaki H, Kitagawa T, Kinoshita M, Baba S, Yamada T, Osawa S, Sugimoto K ( 2012 ) Lymphomatoidgastropathy mimicking extranodal NK/T cell lymphoma, nasal type: a case report. World J Gastroenterol 18:2140 2144. https://doi.org/10.3748/wjg.v18.i17.2140

8. Ishibashi Y, Matsuzono E, Yokoyama F, Ohara Y, Sugai N, Seki H, Miura A, Fujita J, Suzuki J, Fujisawa T, Suzuki A, Hatanaka Y (2013) A case of lymphomatoid gastropathy: a self-limited pseudomalignant natural killer (NK)-cell proliferative disease 
mimicking NK/T-cell lymphomas. Clin J Gastroenterol 6:287-290. https://doi.org/10.1007/s12328-013-0397-7

9. Koh J, Go H, Lee WA, Jeon YK (2014) Benign indolent CD56positive NK-cell lymphoproliferative lesion involving gastrointestinal tract in an adolescent. Korean J Pathol 48:73-76. https://doi. org/10.4132/KoreanJPathol.2014.48.1.73

10. Takata K, Noujima-Harada M, Miyata-Takata T, Ichimura K, Sato Y, Miyata T, Naruse K, Iwamoto T, Tari A, Masunari T, Sonobe H, Okada H, Iwamuro M, Mizobuchi K, Gion Y, Yoshino T (2015) Clinicopathologic analysis of 6 lymphomatoid gastropathy cases: expanding the disease spectrum to CD4-CD8+ cases. Am J Surg Pathol 39:1259-1266. https://doi.org/10.1097/PAS. 0000000000000443

11. Hwang SH, Park JS, Jeong SH, Yim H, Han JH (2016) Indolent NK cell proliferative lesion mimicking NK/T cell lymphoma in the gallbladder. Hum Pathol Case Rep 5:39-42. https://doi.org/10. 1016/j.ehpc.2016.01.004

12. Isom JA, Arroyo MR, Reddy D, Joshi-Guske P, Al-Quran SZ, Li Y, Allan RW (2018) NK cell enteropathy: a case report with 10 years of indolent clinical behaviour. Histopathology 73:345-350. https:// doi.org/10.1111/his.13502

13. Wang R, Kariappa S, Toon CW, Varikatt W (2019) NK-cell enteropathy, a potential diagnostic pitfall of intestinal lymphoproliferative disease. Pathology 51:338-340. https://doi.org/10.1016/j. pathol.2018.09.064

14. Xia D, Morgan EA, Berger D, Pinkus GS, Ferry JA, Zukerberg LR (2019) NK-cell enteropathy and similar indolent lymphoproliferative disorders: a case series with literature review. Am J Clin Pathol 151:75-85. https://doi.org/10.1093/ajcp/aqy108

15. Xiao W, Gupta GK, Yao J, Jang YJ, Xi L, Baik J, Sigler A, Kumar A, Moskowitz AJ, Arcila ME, Raffeld M, Pittaluga S, Dogan A, Jaffe ES (2019) Recurrent somatic JAK3 mutations in NK-cell enteropathy. Blood 134:986-991. https://doi.org/10.1182/blood. 2019001443

16. Krishnan R, Ring K, Williams E, Portell C, Jaffe ES, Gru AA (2020) An enteropathy-like indolent NK-cell proliferation presenting in the female genital tract. Am J Surg Pathol 44:561-565. https://doi.org/10.1097/PAS.0000000000001387

17. Koo M, Olevsky O, Ruchalski K, Song S (2019) Primary intestinal NK-cell lymphoma, EBV-negative: a case report and literature review. Hum Pathol Case Rep 17:200303. https://doi.org/10.1016/j. hpcr.2019.200303

18. Roberti A, Dobay MP, Bisig B, Vallois D, Boéchat C, Lanitis E, Bouchindhomme B, Parrens MC, Bossard C, Quintanilla-Martinez L, Missiaglia E, Gaulard P, de Leval L (2016) Type II enteropathyassociated T-cell lymphoma features a unique genomic profile with highly recurrent SETD2 alterations. Nat Commun 7:12602. https:// doi.org/10.1038/ncomms12602

Publisher's note Springer Nature remains neutral with regard to jurisdictional claims in published maps and institutional affiliations. 